\title{
Insertion of fluorescent fatty acid probes into the outer membranes of the pathogenic spirochaetes Treponema pallidum and Borrelia burgdorferi
}

\author{
David L. Cox ${ }^{1}$ and Justin D. Radolf ${ }^{2,3,4}$ \\ Author for correspondence: David L. Cox. Tel: +1 404639 3446. Fax: + 14046393976 \\ e-mail:dlc6@cdc.gov
}

\footnotetext{
1 The Bacterial STD Branch, Centers for Disease Control and Prevention, Mailstop D-13, 1600 Clifton Rd, Atlanta, GA 30333, USA

2,3,4 The Center for Microbial Pathogenesis ${ }^{2}$ and the Departments of Medicine ${ }^{3}$ and Genetics and Developmental Biology 4 , the University of Connecticut Health Center, Farmington, CT 06030, USA
}

\begin{abstract}
The authors examined the ability of octadecanoyl $\left(C_{18}\right)$, hexadecanoyl $\left(C_{16}\right)$ and dodecanoyl $\left(C_{12}\right)$ fatty acid (FA) conjugates of 5-aminofluorescein (OAF, HAF and DAF, respectively) to insert into the outer membranes (OMs) of Treponema pallidum, Borrelia burgdorferi and Escherichia coli. Biophysical studies have demonstrated that these compounds stably insert into phospholipid bilayers with the acyl chain within the hydrophobic interior of the apical leaflet and the hydrophilic fluorescein moiety near the phospholipid head groups. Consistent with the known poor intrinsic permeability of the E. Coli OM to hydrophobic compounds and surfactants, $E$. coli was not labelled with any of the FA probes. OAF inserted more readily into OMs of $B$. burgdorferi than into those of $T$. pallidum, although both organisms were completely labelled at concentrations at or below $2 \mu \mathrm{g} \mathrm{ml}^{-1}$. Intact spirochaetes were labelled with OAF but not with antibodies against known periplasmic antigens, thereby confirming that the probe interacted exclusively with the spirochaetal OMs. Separate experiments in which organisms were cooled to $4^{\circ} \mathrm{C}$ (i.e. below the OM phase-transition temperatures) indicated that labelling with OAF was due to insertion of the probe into the OMs. B. burgdorferi, but not T. pallidum, was labelled by relatively high concentrations of HAF and DAF. Taken as a whole, these findings support the prediction that the lack of lipopolysaccharide renders $T$. pallidum and $B$. burgdorferi OMs markedly more permeable to lipophilic compounds than their Gram-negative bacterial counterparts. The data also raise the intriguing possibility that these two pathogenic spirochaetes obtain long-chain FAs, nutrients they are unable to synthesize, by direct permeation of their OMs.
\end{abstract}

Keywords: flow cytometry, fatty acid metabolism, membrane fluidity

\section{INTRODUCTION}

Syphilis, a sexually transmitted disorder, and Lyme disease, the most common tick-borne infection in the United States, are caused by the spirochaetal pathogens Treponema pallidum and Borrelia burgdorferi, respectively. A number of studies in the last decade have documented major differences in protein and lipid

Abbreviations: DAF, dodecanoylaminofluorescein; FA, fatty acid; HAF, hexadecanoyl-aminofluorescein; MFI, mean fluorescence intensity; OAF, octadecanoylaminofluorescein; OM, outer membrane; OspA, outer surface protein A; TpCM, T. pallidum cultivation medium. content between the outer membranes (OMs) of these two pathogenic spirochaetes and those of Gram-negative bacteria (Cox et al., 1992; Belisle et al., 1994; Bourell et al., 1994; Radolf, 1995; Walker et al., 1989, 1991). One principal difference is that LPS, the potent proinflammatory glycolipid found in the outer leaflets of Gram-negative bacterial OMs, is absent from the OMs of the two spirochaetes (Fraser et al., 1997, 1998; Radolf et al., 1995a, b). From a physiological standpoint this is potentially important because LPS forms a permeability barrier which limits the penetration of hydrophobic compounds into Gram-negative bacterial OMs (Nikaido, 1996). Indeed, the lack of LPS leads to the 
(a)

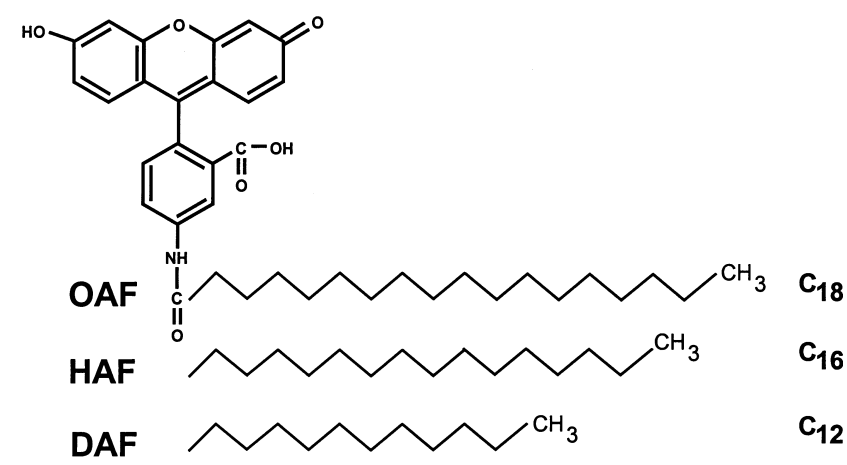

(b)

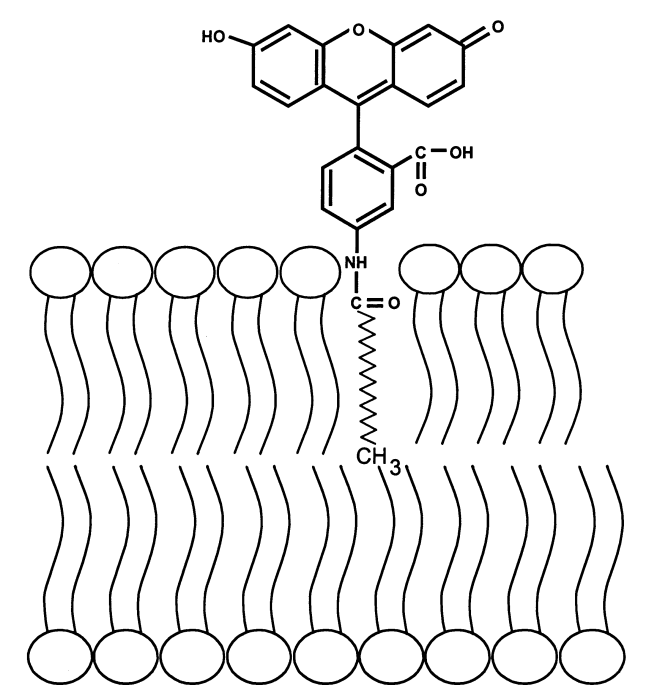

Fig. 1. Probes used in this study. (a) Structures of the $C_{18}$ $\mathrm{C}_{16}$ and $\mathrm{C}_{12}$ FA-5-aminofluorescein conjugates: octadecoylaminofluorescein (OAF), hexadecoylaminofluorescein (HAF) and dodecoylaminofluorescein (DAF). (b) Topology following membrane insertion (adapted from the Molecular Probes website, html://www.probes.com).

prediction that the OMs of the two spirochaetes are more permeable to lipophilic compounds than are their Gram-negative bacterial counterparts.

In recent years, there has been increasing recognition of the relevance of an improved understanding of the physiological properties of spirochaetal OMs to disease pathogenesis. However, studying the permeability properties of $T$. pallidum and B. burgdorferi OMs presents some unique challenges. Unlike E. coli, neither of these spirochaetes can be genetically manipulated, so organisms whose OMs are deficient in specific components cannot be created. Moreover, methods used to study the permeability of Gram-negative bacterial OMs to hydrophilic compounds, which also rely upon the ability to genetically transform the bacteria and express periplasmic enzymes (Heine et al., 1988; Roepe et al., 1990; Treptow \& Shuman, 1985; Vogele et al., 1993), cannot be applied to these organisms. In contrast, methods to study the permeability of spirochaetal OMs to hydrophobic molecules are more readily applicable inasmuch as they require only an intact OM and the availability of lipophilic probes whose insertion into the hydrophobic interior of the OM can be temporally and quantitatively evaluated. In order for a compound to passively diffuse across a membrane, it must first penetrate into the bilayer's hydrophobic interior; insertion, therefore, represents a critical step in the diffusion process and can be regarded as an indicator of membrane permeability.

In this study, we took advantage of two technical developments to assess the relative permeability of $T$. pallidum, B. burgdorferi and E. coli OMs to lipophilic molecules. The first is the commercial availability of a series of fatty acid (FA)-fluorescein conjugates with increasing hydrocarbon chain lengths $\left(\mathrm{C}_{12}, \mathrm{C}_{16}\right.$ and $\mathrm{C}_{18}$; shown Fig. 1a) and thus increasing hydrophobic and amphiphilic properties. Biophysical studies have demonstrated that these compounds stably insert into phospholipid bilayers with the acyl chain within the hydrophobic interior of the apical leaflet and the hydrophilic fluorescein moiety near the leaflet's phospholipid head groups (Fig. 1b) (Christensen et al., 1999; Derzko \& Jacobson, 1980; Haugland, 1996; Sklar et al., 1980; Stolz et al., 1992; Tocanne et al., 1989). In systems containing double membranes, the probes insert exclusively with the outermost lipid bilayer (Blanco et al., 1994; Foley et al., 1986; Tocanne et al., 1989). The second technical development is the use of flow cytometry, which offers many advantages over conventional fluorescence microscopy, most notably the ability to rapidly and quantitatively analyse complex bacterial populations (Boye et al., 1983; Martinez et al., 1982; Shapiro, 1988; Waldman et al., 1987). Our finding that long-chain FAs can insert into the OMs of the two spirochaetes, but not that of E. coli, directly supports the permeability predictions derived from existing models for T. pallidum and B. burgdorferi OM architecture (Cox et al., 1992, 1995, 1996; Radolf et al., 1995a, b). Our data also raise the intriguing possibility that these two pathogenic spirochaetes obtain long-chain FAs, molecules they are unable to synthesize, by direct permeation of their OMs.

\section{METHODS}

Lipophilic probes. Octadecanoyl $\left(\mathrm{C}_{18}\right)$, hexadecanoyl $\left(\mathrm{C}_{16}\right)$ and dodecanoyl $\left(\mathrm{C}_{12}\right)$ FA conjugates of 5 -aminofluorescein (OAF, HAF and DAF, respectively; Fig. 1a) were purchased from Molecular Probes. Unless otherwise noted, stock solutions of the probes were prepared at $1 \mathrm{mg} \mathrm{ml}^{-1}$ in DMSO. Stock solutions were usually made fresh for each experiment, but they can be stored at $4{ }^{\circ} \mathrm{C}$ in the dark. The DMSO will solidify but can be melted at room temperature before dispensing.

Bacterial strains. Treponema pallidum subsp. pallidum (Nichols strain) was propagated in rabbit testes as previously described (Cox et al., 1990). Low-passage $(<5)$ Borrelia burgdorferi (B31 strain) was grown in BSK II broth (Radolf et al., 1994). Spirochaetes were enumerated by dark-field mi- 
croscopy and diluted to a concentration of approximately $1 \times 10^{8} \mathrm{ml}^{-1}$ in the appropriate medium prior to use. Midexponential-phase Escherichia coli C600 (ATCC 23724) was cultivated in tryptone phosphate broth (Difco) at $35^{\circ} \mathrm{C}$.

Labelling procedures and flow cytometry. For labelling of $T$. pallidum with the FA conjugates, probes were added directly to treponemal suspensions freshly harvested at peak orchitis in T. pallidum cultivation medium (TpCM; Cox et al., 1990) containing $10 \%(\mathrm{v} / \mathrm{v})$ heat-inactivated fetal bovine serum. For labelling of B. burgdorferi or E. coli, the probes were added directly to mid-exponential-phase cultures in BSKII medium or tryptone phosphate broth, respectively. Unless otherwise noted, organisms were incubated with the probes for $2 \mathrm{~h}$ at $34{ }^{\circ} \mathrm{C}$. To examine $\mathrm{OM}$ labelling at $4{ }^{\circ} \mathrm{C}$, parallel samples were cooled to $4^{\circ} \mathrm{C}$ before the addition of the probe; during the subsequent analysis by flow cytometry, the injection syringe was maintained at $4^{\circ} \mathrm{C}$ with an ice pack.

Because of the small size of the spirochaetes, particularly T. pallidum $(\leqslant 0 \cdot 2 \mu \mathrm{m}$ in diameter), gating on forward light scatter as a means of tracking the total number of cells within a population was extremely difficult. Consequently, we devised an alternative approach in which the total number of organisms in a suspension was determined by labelling with the vital stain Live/Dead BacLight (Molecular Probes), which has the same emission wavelength as fluorescein and labels all bacteria. The percentage of organisms labelled with a particular FA probe was determined by dividing the number of bacteria labelled with the probe by the number of viable organisms detected with Live/Dead BacLight. Because E. coli did not label with any of the FA probes (see below), Live/Dead BacLight also was used to confirm that labelled E. coli could be detected by the cytometer and to establish gating parameters for this bacterium (data not shown).

Flow cytometry was performed using a Bruker ACR 1400 cytometer (Bruker Instruments). Cells were analysed at a flow rate of $500 \pm 100$ cells s$^{-1}$ until 25000 events had been collected. Triggering was set routinely for green fluorescence rather than forward light scatter as noted above. During sample analysis, the cytometer generated two-dimensional histograms consisting of forward light scatter ( $x$ axis) versus fluorescence intensity ( $y$ axis) for each fluorescent organism detected. Cytometric gates were established to monitor each bacterial population. The accuracy of the 'percentage labelled' determinations was enhanced by the fact that the Bruker cytometer not only counts the number of fluorescent bacteria within a gate, but also monitors the volume of sample injected, so that a bacterial concentration per $\mathrm{ml}$ can be calculated. An internal control of $0.9 \mu \mathrm{m}$ diameter green fluorescent beads (Duke Scientific) was present in each sample to aid in maintaining instrument alignment and to ensure that each sample was analysed under optimal optical conditions. Because of small variations in cell size and the asymmetrical geometry of the spirochaetes, the signals which represent the fluorescence intensity of a population of spirochaetes are scattered over many channels of the fluorescence detectors. The mean fluorescence intensity (MFI), the mean channel of that range for a given population, is provided by the cytometer as the samples are being analysed. Four or five separate analyses were performed on each sample for each time point (100000 to 125000 total events) and each experiment was repeated at least twice.

Double-label experiments of spirochaetes encapsulated in gel microdroplets. To confirm that the FA-fluorescein conjugates inserted exclusively into the OMs of intact spirochaetes, double-label experiments were performed as follows.
Spirochaetes were encapsulated into low-melting-point agarose (Sigma, Type IX) gel microdroplets as previously described (Cox et al., 1995, 1996). Briefly, suspensions of bacteria were warmed to $40{ }^{\circ} \mathrm{C}$ in a $50 \mathrm{ml}$ round-bottom glass tube and mixed $1: 1$ with a warmed solution of $2 \%(\mathrm{w} / \mathrm{v})$ lowmelting-point agarose. Unless otherwise noted, the tubes were flushed with $95 \% \mathrm{~N}_{2} / 5 \% \mathrm{CO}_{2}(\mathrm{v} / \mathrm{v})$ in each of these steps to protect the spirochaetes from oxygen toxicity. The suspension was vigorously vortexed as $5 \mathrm{ml}$ warm $\left(40^{\circ} \mathrm{C}\right)$ mineral oil was added. The solution was allowed to mix for another 15-20 s until an emulsion formed, and then the tube was set in an icewater bath $\left(4^{\circ} \mathrm{C}\right)$ for $10 \mathrm{~min}$. The beads were collected by washing the oil/agarose mix twice with $5 \mathrm{ml}$ TpCM containing $10 \%$ fetal bovine serum. The aqueous (bottom) layers were pooled from each extraction and washed an additional three times with $10 \mathrm{ml} \mathrm{TpCM}$ to remove any remaining oil as described above and $1 \mathrm{ml}$ portions of the pooled bead preparations were placed into several $12 \times 75 \mathrm{~mm}$ polypropylene tubes. Two tubes were designated for each antibody used (one with $0.05 \%, \mathrm{w} / \mathrm{v}$, Triton X-100 and one without). For T. pallidum, the beads in each tube were probed for $2 \mathrm{~h}$ with OAF and rat antisera against either endoflagella or the $47 \mathrm{kDa}$ lipoprotein (Tp47) (Cox et al., 1995). For B. burgdorferi, the beads in each tube were probed with OAF and rat antisera against endoflagella, outer-surface lipoprotein A (OspA) (Cox et al., 1996) or p39 (BmpA) (Simpson et al., 1991). The beads were washed three times with TpCM and then probed with the Alexa 546 conjugate of goat anti-rat antibody (Molecular Probes) for 1.5 h. The beads were again washed twice with TpCM and then the detergent-treated beads were split into two equal aliquots. OAF was added at a concentration of $3 \mu \mathrm{g} \mathrm{ml}^{-1}$ to the beads without detergent and to one aliquot of the beads treated with Triton X-100. To demonstrate that Triton X-100 did not quench fluorescence, $0.05 \%$ Triton X-100 was added back with the OAF to the detergent-treated beads. Each experiment was repeated three times.

Microscopy. Microscopic observations of the labelled suspensions and bead preparations were performed using a Nikon Optiphot (Nikon) fluorescence microscope equipped with a dark-field condenser. Photomicrographs were prepared using a Nikon camera mounted on the fluorescence scope. Fuji 1600 ASA colour film was used to capture images; the exposure time, unless otherwise noted, was $1 \mathrm{~s}$ for both darkfield and fluorescence images.

Statistics. All data were analysed using the paired student $t$-test. The analyses were performed using the statistical program Systat (Systat, Evanston, IL, USA) on a Macintosh 8500 computer. Each group was independently compared with other groups in each experiment. The statistical data presented consist of the probability $(P)$ for each test. The standard deviation and error bar values were the standard deviations of the mean values from each experiment.

\section{RESULTS AND DISCUSSION}

\section{Flow cytometric assessment of labelling with OAF}

We began our study by assessing the ability of graded concentrations of OAF, the most lipophilic and amphiphilic of the three conjugates shown in Fig. 1(a), to label T. pallidum subsp. pallidum (Nichols), low-passage $B$. burgdorferi $\mathrm{B} 31$ and E. coli C600. Labelling of E. coli was not detected at any concentration of OAF (Fig. 2a). In additional experiments, labelling of E. coli was not 
(b)
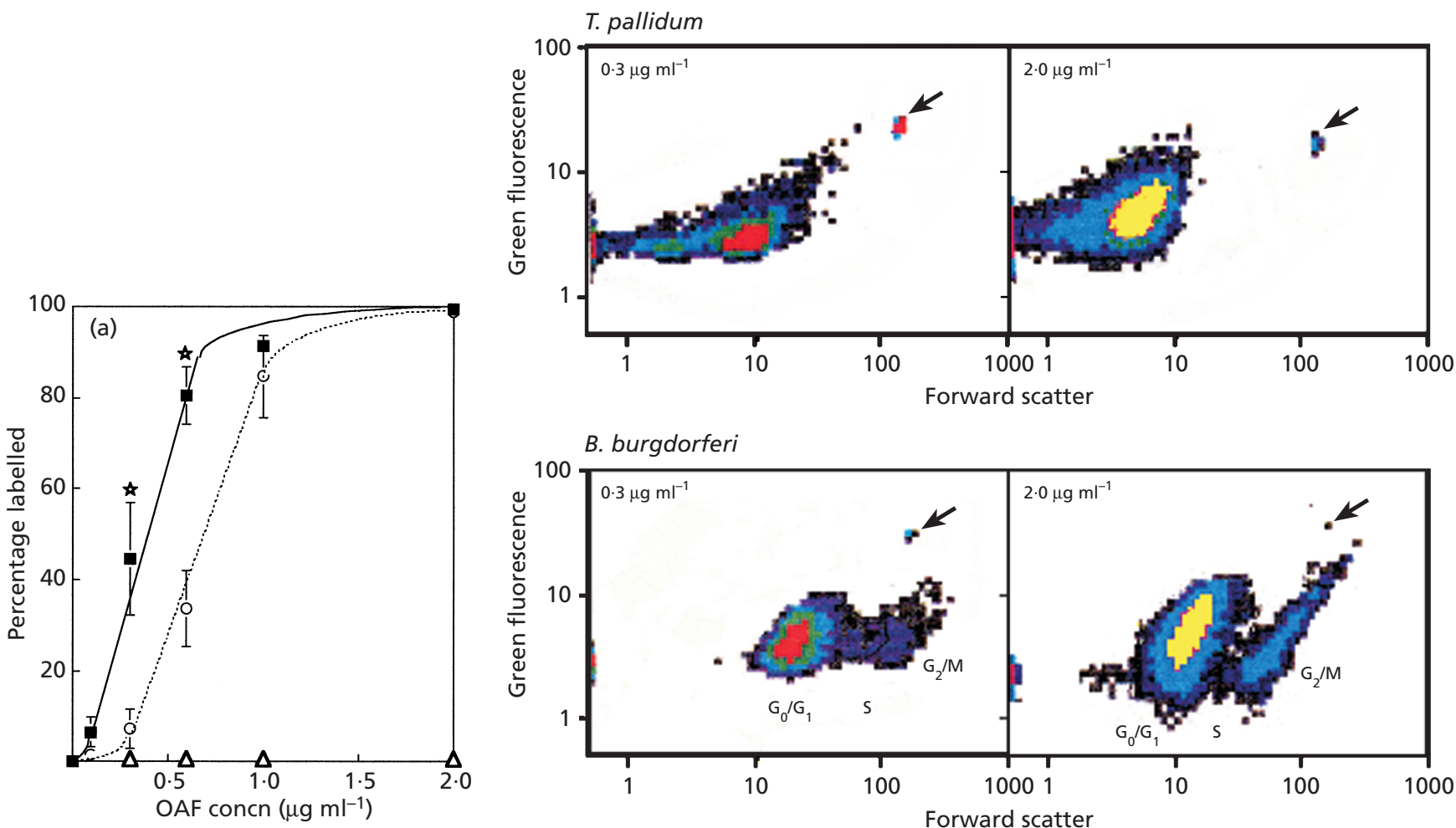

B. burgdorferi

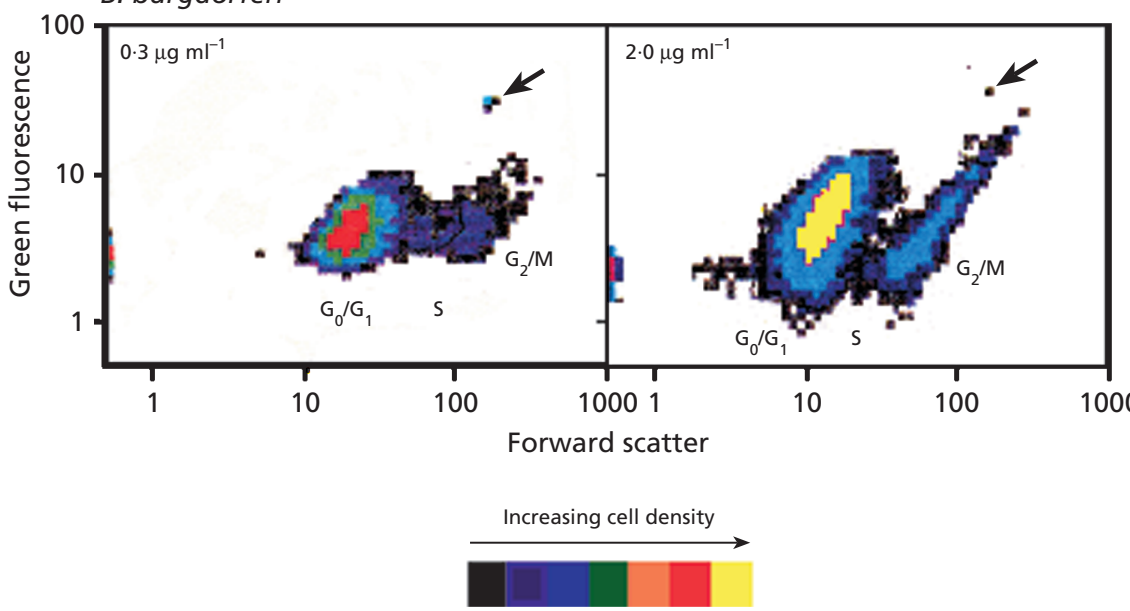

Fig. 2. (a) T. pallidum $(O)$, B. burgdorferi $(\boldsymbol{\square})$ and $E$. coli $(\triangle)$ were analysed by flow cytometry following incubation with graded concentrations of OAF. The percentages of organisms labelled are shown as a function of OAF concentration. The percentage of organisms labelled was determined by dividing the number of bacteria labelled with the probe by the number of viable organisms detected with Live/Dead BacLight. Data are expressed as the means of three experiments \pm standard deviation. Asterisks denote values which were significantly different. (b) Representative 2D histograms obtained following incubation of $T$. pallidum and $B$. burgdorferi with 0.3 and $2.0 \mu \mathrm{g} \mathrm{OAF} \mathrm{ml} \mathrm{O}^{-1}$. Cytometric gates have been removed to simplify the diagrams. The arrow indicates the $0.9 \mu \mathrm{m}$ green beads used as an internal standard. The $B$. burgdorferi histograms are labelled to indicate the phase of the cell cycle $\left(G_{0} / G_{1}, S\right.$ and $\left.G_{2} / M\right)$ represented by each population.

observed at OAF concentrations as high as $100 \mu \mathrm{g} \mathrm{ml}^{-1}$ or when the coliforms were washed and resuspended in phosphate-buffered saline ( $\mathrm{pH} 7 \cdot 4)$ prior to incubation with the probe (data not shown). These results are consistent with the poor intrinsic permeability of the $E$. coli OM to hydrophobic compounds and surfactants (Nikaido, 1996). In contrast, both T. pallidum and B. burgdorferi showed concentration-dependent increases in labelling, with significantly greater labelling of $B$. burgdorferi $(P<0 \cdot 001)$ at $0 \cdot 3$ and $0 \cdot 6 \mu \mathrm{g} \mathrm{ml}^{-1}$ (Fig. 2a). The forward light scatter signal (shift to the right) for $B$. burgdorferi was stronger than that for $T$. pallidum because of the Lyme disease spirochaete's larger size. Time-course studies showed that, at each concentration, labelling of the spirochaete populations reached steady state by $20 \mathrm{~min}$ (data not shown); the failure of organisms to label, therefore, was not due to an insufficient period of incubation with the probe.
Interestingly, for both spirochaetes, concentrationdependent increases in the proportion of labelled cells occurred without significant increases in MFI. Had the MFI increased, the position of the spirochaetal populations in the histograms would have shifted upwards; no shift, however, was ever observed. Representative histograms (Fig. 2b) are shown for $0.3 \mu \mathrm{g} \mathrm{ml}^{-1}$, the lowest OAF concentration at which labelling was detected in both organisms, and $2 \cdot 0 \mu \mathrm{g} \mathrm{ml}^{-1}$, a concentration at which both populations were completely labelled (Fig. 2a). We believe this phenomenon reflects (i) heterogeneity in OM lipid composition within the spirochaetal population such that individual organisms have different 'threshold concentrations' for labelling and (ii) the fact that once a threshold concentration for labelling is reached for a particular organism, a saturating amount of label is taken up by its OM. That labelled organisms were indeed saturated was supported by the finding that 

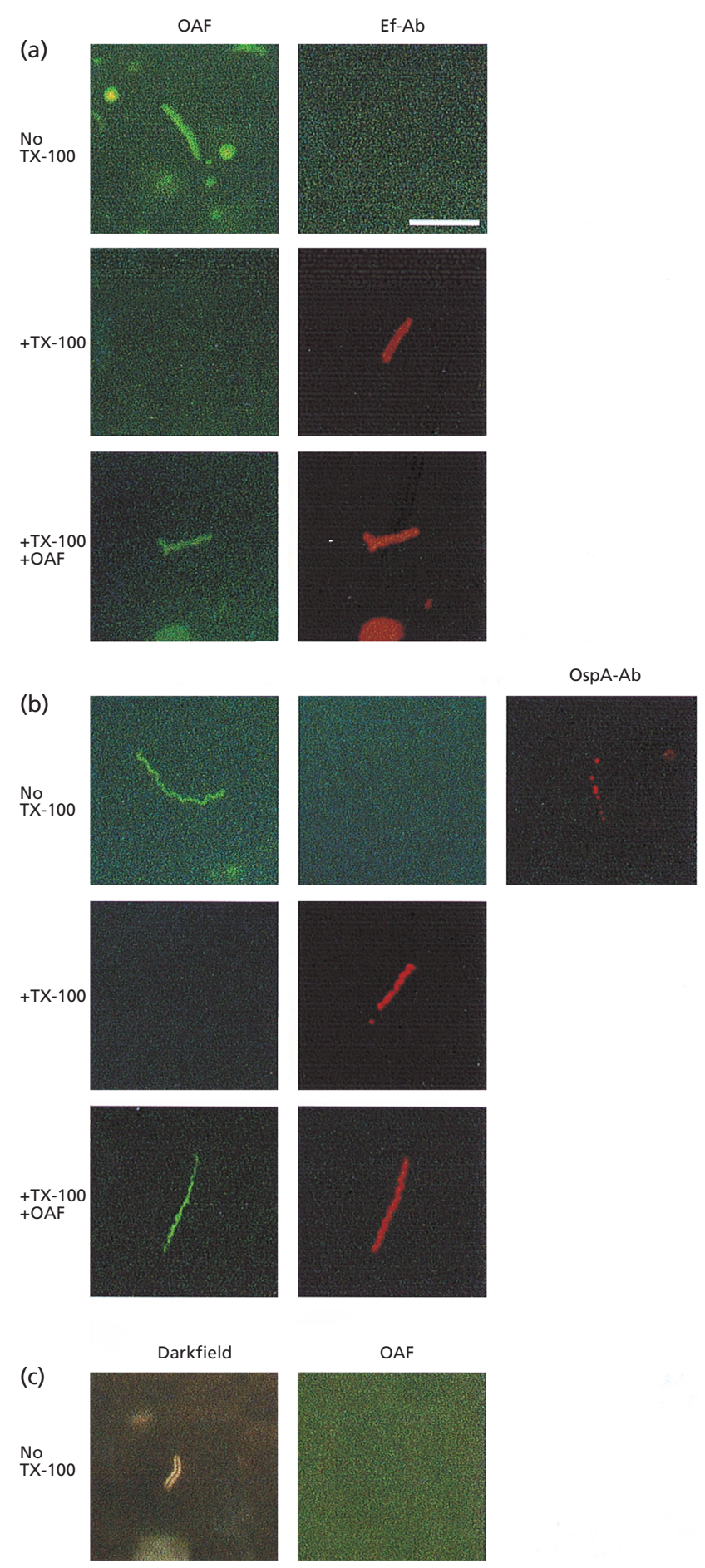

Fig. 3. (a, b) $O M$ localization of $O A F$ in $T$. pallidum (a) and $B$. burgdorferi (b). Organisms encapsulated in agarose gel microdroplets were probed in the absence or presence of $0.05 \%$ Triton X-100 with $\operatorname{OAF}\left(2 \mu \mathrm{g} \mathrm{ml}^{-1}\right)$ and rat antibodies against endoflagella (Ef-Ab) for $2 \mathrm{~h}$ at $34^{\circ} \mathrm{C}$. One set of $B$. burgdorferi was also probed with $\mathrm{OAF}$ and antibodies against OspA (OspA-Ab). Bound antibodies were detected by probing with the Alexa 546 conjugate of goat anti-rat IgG. OAF $\left(2 \mu \mathrm{g} \mathrm{ml}^{-1}\right)$ was added back to one portion of the beads treated with the detergent. To demonstrate that Triton X-100 did not quench fluorescence, $0.05 \%$ Triton X-100 was added back with the OAF to the detergent-treated beads; under these increases in MFI did not occur at even greater OAF concentrations (up to $10 \mu \mathrm{g} \mathrm{ml}^{-1}$; data not shown). Analysis of non-synchronized growing cultures of bacteria by flow cytometry commonly reveals a distinct, large population of average-sized cells on the left $\left(G_{0} / G_{1}\right)$; a small population of larger cells undergoing cell division on the right $\left(G_{2} / M\right)$, and a much smaller population of intermediate-sized cells about to enter cell division (S phase) (Boye et al., 1983; Shapiro, 1988). Also noteworthy was that the histograms of $B$. burgdorferi fit this model for typical cell-cycle distribution (Fig. 2b). The absence of comparably shifted treponemal subpopulations is consistent with the syphilis spirochaete's slower doubling time and the fact that treponemes harvested at peak orchitis are most likely at or near stationary phase (Akins et al., 1998; Magnuson et al., 1948).

\section{FA-fluorescein conjugates insert into the OMs of intact spirochaetes}

The biophysical properties of OAF lead to the prediction that it will insert into and remain trapped within the first bilayer it encounters (Christensen et al., 1999; Foley et al., 1986; Haugland, 1996; Stolz et al., 1992), which, in the case of intact T. pallidum and B. burgdorferi, would be the spirochaetal OMs (Blanco et al., 1994). Two experimental approaches were pursued to confirm this important contention.

In one series of experiments, organisms encapsulated in agarose gel microdroplets were probed simultaneously with OAF $\left(2 \mu \mathrm{g} \mathrm{ml}^{-1}\right.$ for $2 \mathrm{~h}$ at $\left.34^{\circ} \mathrm{C}\right)$ and with specific antibodies in the absence or presence of $0.05 \%$ Triton $\mathrm{X}-100$, a detergent concentration which selectively removes the OMs of both spirochaetes (Akins et al., 1998; Caimano et al., 1999; Cox et al., 1995, 1996; Lahdenne et al., 1997; Shevchenko et al., 1997, 1999). The antibodies were directed against targets whose cellular locations in T. pallidum and/or B. burgdorferi have been well documented (Cox et al., 1996; Radolf et al., 1995a, b; Simpson et al., 1991). Representative micrographs are shown in Fig. 3. Consistent with the above flow-cytometry studies, all of the encapsulated spirochaetes were labelled by OAF at the concentration tested (Fig. 3a, b, top row, left panels), whereas labelling of $E$. coli was not discernible under the same conditions (Fig. 3c). No binding of anti-flagellar antibodies to either T. pallidum or B. burgdorferi was observed in the absence of detergent, confirming that the OMs of the two spirochaetes were intact (Fig. 3a, b, top row, right panels). Further evidence for this was provided by the observation that antibodies also failed to bind to two other T. pallidum and B. burgdorferi periplasmic antigens, Tp47 and p39 (BmpA), respectively (data not shown). In the absence of detergent, however, $B$.

conditions, the cytoplasmic membranes become labelled with the OAF. (c) E. coli was probed with only OAF $\left(2 \mu \mathrm{g} \mathrm{ml}^{-1}\right.$ for $2 \mathrm{~h}$ at $34^{\circ} \mathrm{C}$ ). Representative micrographs are shown. Bar, $10 \mu \mathrm{m}$. 


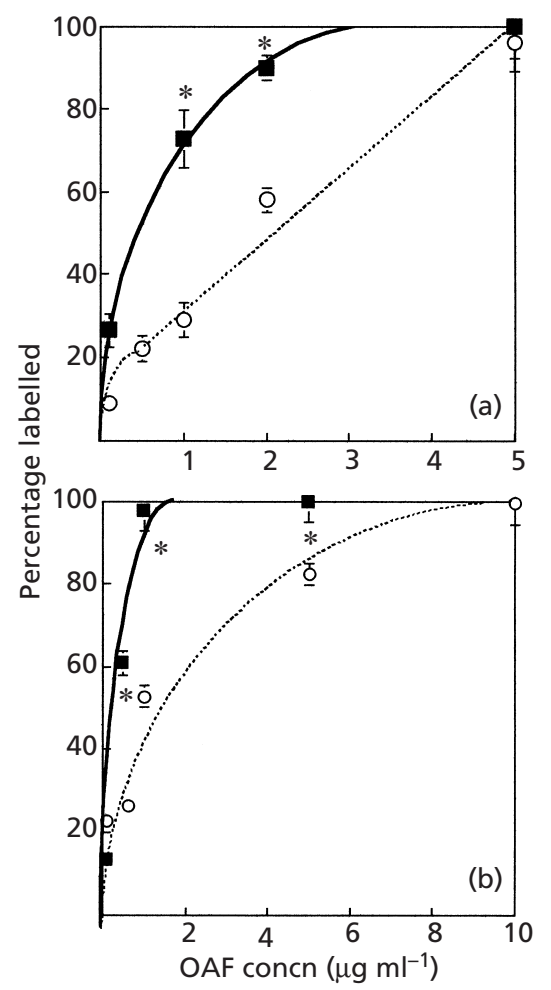

Fig. 4. Insertion of OAF into spirochaetal OMs is temperaturedependent. $T$. pallidum (a) and $B$. burgdorferi (b) were incubated with graded concentrations of OAF at $37^{\circ} \mathrm{C}(\boldsymbol{\square})$ or $4{ }^{\circ} \mathrm{C}(\bigcirc)$. The percentage of labelled organisms is shown as a function of the concentration of OAF (note the different concentration scales in panels $a$ and b). Data are expressed as the means of three experiments \pm standard deviation. Asterisks denote values which were significantly different $(P<0.001)$.

burgdorferi was labelled simultaneously with antibodies directed against OspA (Fig. 3b, top row, far right panel). Comparable labelling experiments could not be performed with $T$. pallidum because its surface antigens have not yet been definitively identified (Fraser et al., 1998). In contrast, OAF labelling was lost when spirochaetes were incubated with detergent (Fig. 3a, b, middle row, left panels). Moreover, detergent-treated organisms were readily labelled with antibodies directed against flagellin (Fig. 3a, b, middle row, right panels), Tp47 (not shown) and p39 (not shown), thereby demonstrating that the OMs had indeed been removed by the detergent treatment. When OAF was added back to the detergent-treated spirochaetes, they once more became labelled (Fig. 3a, b, bottom row, left panels). These findings demonstrate that OAF can insert into cytoplasmic membranes once OMs are removed and that Triton X-100 does not quench the fluorescence of the probe.

Having established that the probe was associated exclusively with the OMs of both T. pallidum and $B$. burgdorferi, we next sought additional evidence that labelling involved actual insertion into the bilayer. A second series of experiments took advantage of the fact
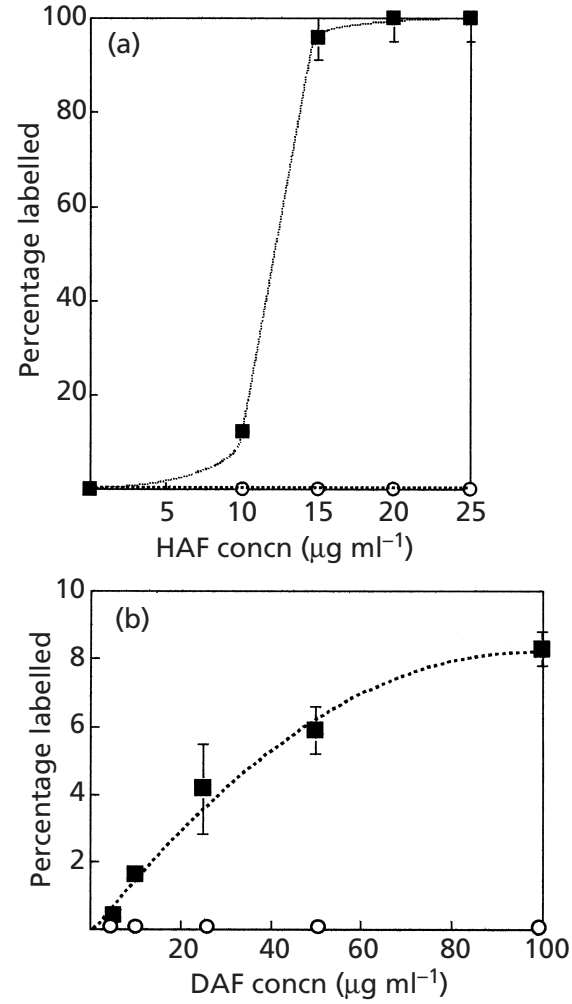

Fig. 5. HAF and DAF insert into OMs of some $B$. burgdorferi, but not $T$. pallidum. (a) The percentages of labelled spirochaetes ( $\square$, B. burgdorferi; $\bigcirc, T$. pallidum) are shown as a function of HAF concentration (a) or DAF concentration (b). Data are expressed as the means of three experiments + standard deviation. E. coli did not label with either probe and is not shown.

that penetration of lipophilic compounds is retarded at temperatures below a membrane's liquid crystalline to gel phase-transition temperature, while simple adsorption to the bacterial surface tends to be independent of membrane fluidity (Gennis, 1989a, b). As shown in Fig. 4, a marked decrease in concentration-dependent labelling of both spirochaetes was observed at $4{ }^{\circ} \mathrm{C}$, a temperature below the phase-transition temperatures for both OMs (Bourell et al., 1994; Radolf et al., 1994). Interestingly, even at the lower temperature, OAF penetrated more efficiently into the B. burgdorferi OM.

\section{Relatively high concentrations of HAF and DAF can label intact $B$. burgdorferi but not $T$. pallidum}

Neither T. pallidum nor E. coli was labelled by HAF at concentrations up to $100 \mu \mathrm{g} \mathrm{ml}^{-1}$ (Fig. 5a and data not shown). B. burgdorferi, in contrast, was labelled by this reagent. Appreciable labelling with HAF, however, required a concentration greater than $5 \mu \mathrm{g} \mathrm{ml}^{-1}$, while $50 \%$ and $100 \%$ labelling occurred at approximately $12 \mu \mathrm{g} \mathrm{ml}^{-1}$ and $20 \mu \mathrm{g} \mathrm{ml}^{-1}$, respectively (Fig. 5a). Also noteworthy was the slope of the HAF curve in comparison to that for OAF (compare Figs $2 \mathrm{a}$ and $5 \mathrm{a}$ ), indicating that borrelial OMs have a wider threshold 
(10-15 $\mu \mathrm{g} \mathrm{ml}^{-1}$ ) for labelling with HAF as opposed to the narrower range of concentrations $\left(0 \cdot 1-1 \cdot 0 \mu \mathrm{g} \mathrm{ml}^{-1}\right)$ at which OAF inserts into the OMs. As with OAF, the MFI of the labelled organisms did not show a concentration-dependent increase. To determine if the lack of labelling of T. pallidum with HAF reflected an intrinsic property of the treponemal OM that was constant throughout the cell cycle, HAF at $100 \mu \mathrm{g} \mathrm{ml}^{-1}$ was added to growing cultures of T. pallidum cocultivated with Sf1Ep cells (Cox et al., 1990). Although the epithelial cells avidly took up the dye, no labelling of T. pallidum was observed during a $7 \mathrm{~d}$ period in which the treponemal cell density increased approximately 40 fold (data not shown). The lack of permeability of the treponemal $\mathrm{OM}$ to HAF was surprising in light of previous studies showing that T. pallidum can assimilate radiolabelled palmitate into cellular lipids and lipoproteins (Belisle et al., 1994; Chamberlain et al., 1989). This apparent inconsistency can be explained by the fact that steric hindrance caused by the fluorescein moiety reduces the length of hydrocarbon chain effectively available for insertion into the membrane (Molecular Probes, personal communication). Finally, we also examined the permeability of $T$. pallidum and $B$. burgdorferi to DAF, the least lipophilic and amphiphilic of the three FA conjugates. As with HAF, no labelling of T. pallidum or E. coli was detected with concentrations up to $100 \mu \mathrm{g} \mathrm{ml}^{-1}$, whereas B. burgdorferi was slightly permeable. Approximately $8 \%$ of the borreliae were labelled at the maximum DAF concentration tested (Fig. $5 b)$.

\section{Spirochaetal OMs and lipophilic molecules - implications for FA uptake}

In this study, we examined the ability of FA-fluorescein conjugates to insert into the OMs of T. pallidum and $B$. burgdorferi, but not into that of E. coli. Although these amphiphilic probes do not extend beyond the outer leaflet of the bilayer, insertion into the hydrophobic interior of the membrane is a prerequisite for passive diffusion and can be considered an indicator of the membrane's relative permeability to these compounds under investigation. Our findings that T. pallidum and $B$. burgdorferi, but not E. coli, were labelled by OAF and/or HAF and DAF support the prediction that the absence of LPS renders the OMs of these two pathogenic spirochaetes relatively permeable to lipophilic compounds. Two other findings also are noteworthy. The first is that labelling spirochaetes within a population occurred over a range of OAF and HAF concentrations, a result suggesting variability of OM lipid constituents among individual bacteria. Christensen et al. (1999) also noted heterogeneous labelling of mycobacterial populations incubated with the same probe, indicating that organism-to-organism variability in lipid constituents is not limited to spirochaetes. The second noteworthy finding is the relatively greater ability of lipophilic compounds to insert into $B$. burgdorferi OMs as compared to those of $T$. pallidum. The disparate properties of the two spirochaetal OMs presumably reflect previously noted differences in their lipid constituents and the greater relative abundance of unsaturated FAs in borrelial cellular lipids (Belisle et al., 1994; Radolf et al., 1995a, b). Biophysical studies of natural and artificial membranes have shown that increased levels of unsaturated FAs can be particularly important for enhancing membrane fluidity (Araiso et al., 1990).

Because the E. coli OM is impermeable to long-chain FAs, a specialized transport protein, FadL, is needed to transport these compounds across the OM; they then passively diffuse across the cytoplasmic membrane (Clark \& Cronan, 1996). Both T. pallidum and B. burgdorferi are incapable of elongating, $\beta$-oxidizing or desaturating long-chain FAs and therefore are entirely dependent upon environmental sources for these molecules (Belisle et al., 1994; Fraser et al., 1997, 1998; Schiller \& Cox, 1977). The absence of an identifiable FA transporter in the genomes of both spirochaetes (Fraser et al., 1997, 1998) appears to necessitate an alternative mechanism for OM transport of long-chain FAs. The studies presented here enable us to postulate that T. pallidum and B. burgdorferi obtain these essential nutrients, most likely in their uncharged protonated forms, by passive diffusion across their OMs. Such a process is also consistent with the slow growth rates of both parasites (Akins et al., 1998; Magnuson et al., 1948). The presumptive impermeability of the $T$. pallidum OM to FAs with shorter hydrocarbon chain lengths may be the result of an adaption to the range of FAs found in human tissues; oleic acid $\left(\mathrm{C}_{18}\right)$, palmitic $\left(\mathrm{C}_{16}\right)$ and linoleic $\left(\mathrm{C}_{18}\right)$ acids are, in that order, the most prevalent FAs in human fat (Cramer \& Brown, 1943). The ability of B. burgdorferi to take up a wider range of FAs than T. pallidum, an obligate pathogen of humans, may reflect the Lyme disease spirochaete's need to adapt to more diverse environments found in both arthropod and mammalian hosts.

\section{ACKNOWLEDGEMENTS}

This research was supported in part by US Public Health Service grants AI-26756 and AI-29735 from the National Institute of Allergy and Infectious Diseases to J.D.R. We are indebted to Ken Bourell for expert assistance with graphics and to Tom Schwann for providing antisera to recombinant p39.

\section{REFERENCES}

Akins, D. R., Bourell, K. W., Caimano, M. J., Norgard, M. V. \& Radolf, J. D. (1998). A new animal model for studying Lyme disease spirochaetes in a mammalian host-adapted state. J Clin Invest 101, 2240-2250.

Araiso, T., Saito, H., Shirahama, H. \& Koyama, T. (1990). Analysis for the molecular motion of phospholipid bilayer with picosecond fluorometry. Biorheology 27, 375-387.

Belisle, J. T., Brandt, M. E., Radolf, J. D. \& Norgard, M. V. (1994). Fatty acids of Treponema pallidum and Borrelia burgdorferi lipoproteins. J Bacteriol 176, 2151-2157.

Blanco, D. R., Reimann, K., Skare, J., Champion, C., Foley, D., Exner, M. M., Handcock, R. E., Miller, J. N. \& Lovett, M. A. (1994). 
Isolation of the outer membrane from Treponema pallidum and Treponema vincentii. J Bacteriol 176, 6088-6099.

Bourell, K. W., Schulz, W., Norgard, M. V. \& Radolf, J. D. (1994). Treponema pallidum rare outer membrane proteins: analysis of mobility by freeze-fracture electron microscopy. J Bacteriol 176, 1598-1608.

Boye, E., Steen, H. B. \& Skarstad, K. (1983). Flow cytometry of bacteria: a promising tool in experimental and clinical microbiology. J Gen Microbiol 129, 973-980.

Bunikis, J. \& Barbour, A. G. (1998). Access of antibody or trypsin to an integral outer membrane protein (P66) of Borrelia burgdorferi is hindered by Osp lipoproteins. Infect Immun $\mathbf{6 7}$, 2874-2883.

Caimano, M. J., Bourell, K. W., Bannister, T. D., Cox, D. L. \& Radolf, J. D. (1999). The Treponema denticola major sheath protein is predominantly periplasmic and has only limited surface exposure. Infect Immun 67, 4072-4083.

Chamberlain, N. R., Brandt, M. E., Erwin, A. L., Radolf, J. D. \& Norgard, M. V. (1989). Major integral membrane protein immunogens of Treponema pallidum are proteolipids. Infect Immun 57, 2872-2877.

Christensen, H., Garton, N. J., Horobin, R. W., Minnikin, D. E. \& Barer, M. R. (1999). Lipid domains of mycobacteria studies with fluorescent molecular probes. Mol Microbiol 31, 1561-1572.

Clark, D. P. \& Cronan, J. E., Jr (1996). Two-carbon compounds and fatty acids as carbon sources. In Escherichia coli and Salmonella: Cellular and Molecular Biology, pp. 343-357. Edited by F. C. Neidhart and others. Washington, DC: American Society for Microbiology.

Cox, D. L., Riley, B., Chang, P., Sayahtaheri, S., Tassell, S. \& Hevelone, J. (1990). Effects of molecular oxygen, oxidationreduction potential, and antioxidants upon in vitro replication of Treponema pallidum subsp. pallidum. Appl Environ Microbiol 56, 3063-3072.

Cox, D. L., Chang, P., McDowell, A. \& Radolf, J. D. (1992). The treponemal outer membrane, not an outer coat of host proteins, is responsible for the limited antigenicity of virulent Treponema pallidum. Infect Immun 60, 1076-1083.

Cox, D. L., Akins, D. R., Porcella, S. F., Norgard, M. V. \& Radolf, J. D. (1995). Treponema pallidum in gel microdroplets: a novel strategy for investigation of treponemal molecular architecture. Mol Microbiol 15, 1151-1164.

Cox, D. L., Akins, D. R., Bourell, K. W., Lahdenne, P., Norgard, M. V. \& Radolf, J. D. (1996). Limited surface exposure of Borrelia burgdorferi outer surface lipoproteins. Proc Natl Acad Sci U S A 93, 7973-7978.

Cramer, D. L. \& Brown, J. B. (1943). Component fatty acids of human depot fat. J Biol Chem 151, 427-438.

Derzko, Z. \& Jacobson, K. (1980). Comparative lateral diffusion of fluorescent lipid analogues in phospholipid multibilayers. Biochemistry 19, 6050-6057.

Foley, M., MacGregor, A. N., Kusel, J. R., Garland, P. B., Bownie, T. \& Moore, I. (1986). The lateral diffusion of lipid probes in the surface membrane of Schistosoma mansoni. J Cell Biol 103, 807-818.

Fraser, C. M., Casjens, S., Huang, W. M. \& 35 other authors (1997). Genomic sequence of a Lyme disease spirochaete, Borrelia burgdorferi. Nature 390, 580-586.

Fraser, C. M., Norris, S. J., Weinstock, G. M. \& 30 other authors (1998). Complete genome sequence of Treponema pallidum, the syphilis spirochaete. Science 281, 375-388.

Gennis, R. B. (1989a). Interactions of small molecules with membranes: partitioning, permeability, and electrical effects. In Biomembranes: Molecular Structure and Function, pp. 235-269. Berlin \& New York: Springer.

Gennis, R. B. (1989b). The structures and properties of membrane lipids. In Biomembranes: Molecular Structure and Function, pp. 36-84. Berlin \& New York: Springer.

Haugland, R. P. (1996). Handbook of Fluorescent Probes and Research Chemicals. Eugene, OR: Molecular Probes.

Heine, H. G., Francis, G., Lee, K. S. \& Ferenci, T. (1988). Genetic analysis of sequences in maltoporin that contribute to binding domains and pore structure. J Bacteriol 170, 1730-1738.

Lahdenne, P., Porcella, S. F., Hagman, K. E., Akins, D. R., Popova, T. G., Cox, D. L., Katona, L. I., Radolf, J. D. \& Norgard, M. V. (1997). Molecular characterization of a 6.6-kilodalton Borrelia burgdorferi outer membrane-associated lipoprotein (lp6.6) which appears to be downregulated during mammalian infection. Infect Immun 65, 412-421.

Magnuson, H. J., Eagle, H. \& Fleischman, R. (1948). The minimal infectious inoculum of Spirochaeta pallida (Nichols strain), and a consideration of its rate of multiplication in vivo. Am J Syph Gon Vener Dis 32, 1-19.

Martinez, O. V., Gratzner, H. G. \& Malinin, T. I. (1982). The effect of beta-lactam antibiotics on Escherichia coli studied by flow cytometry. Cytometry 3, 129-133.

Nikaido, H. (1996). Outer membrane. In Escherichia coli and Salmonella: Cellular and Molecular Biology, pp. 29-47. Edited by F. C. Neidhart and others. Washington, DC: American Society for Microbiology.

Radolf, J. D. (1995). Treponema pallidum and the quest for outer membrane proteins. Mol Microbiol 16, 1067-1073.

Radolf, J. D., Norgard, M. V. \& Schulz, W. W. (1989). Outer membrane ultrastructure explains the limited antigenicity of virulent Treponema pallidum. Proc Natl Acad Sci USA 86 , 2051-2055.

Radolf, J. D., Bourell, K. W., Akins, D. R., Brusca, J. S. \& Norgard, M. V. (1994). Analysis of Borrelia burgdorferi membrane architecture by freeze-fracture electron microscopy. J Bacteriol 176, 21-31.

Radolf, J. D., Goldberg, M. S., Bourell, K. W., Baker, S. I., Jones, J. D. \& Norgard, M. V. (1995a). Characterization of outer membranes isolated from Borrelia burgdorferi, the Lyme disease spirochaete. Infect Immun 63, 2154-2163.

Radolf, J. D., Robinson, E. J., Bourell, K. W., Akins, D. R., Porcella, S. F., Weigel, L. M., Jones, J. D. \& Norgard, M. V. (1995b). Characterization of outer membranes isolated from Treponema pallidum, the syphilis spirochaete. Infect Immun 63, 4244-4252.

Roepe, P. D., Consler, T. G., Menges, M. E. \& Kuback, H. R. (1990). The Lac permease of Escherichia coli. Site directed mutagenic studies on the mechanism of $\beta$-galactoside $/ \mathrm{H}^{+}$symport. Res Microbiol 141, 290-308.

Schiller, N. L. \& Cox, C. D. (1977). Catabolism of glucose and fatty acids by virulent Treponema pallidum. Infect Immun 16, 60-68.

Shapiro, H. M. (1988). Practical Flow Cytometry, 2nd edn. New York: Alan R. Liss.

Shevchenko, D. V., Akins, D. R., Robinson, E., Li, M., Popova, T. G., Cox, D. L. \& Radolf, J. D. (1997). Molecular characterization and cellular location of TpLRR, a processed leucine-rich repeat protein of Treponema pallidum, the syphilis spirochete. $J$ Bacteriol 179, 3188-3195.

Shevchenko, D. V., Sellati, T. J., Robinson, E., Cox, D. L., Shevchenko, O. V., Robinson, E. \& Radolf, J. D. (1999). Membrane topology and cellular location of the Treponema pallidum 
glycerophosphodiester phosphodiesterase (GlpQ) ortholog. Infect Immun 67, 2266-2276.

Simpson, W. J., Schrumpf, M. E., Hayes, S. F. \& Schwan, T. G. (1991). Molecular and immunological analysis of a polymorphic periplasmic protein of Borrelia burgdorferi. J Clin Microbiol 29, 1940-1948.

Sklar, L. A., Doody, M. C., Gotto, A. M. \& Pownall, H. J. (1980). Serum lipoprotein structure: resonance energy transfer localization of fluorescent lipid probes. Biochemistry 19, 1294-1301.

Stolz, D. B., Mahoney, M. G. \& Jacobson, B. S. (1992). The impenetrability of 5-( $N$-hexadecanoyl) aminofluorescein through endothelial cell monolayers is dependent upon its solution properties, not the presence of tight junctions. Biochem Biophys Res Commun 184, 160-166.

Tocanne, J. F., Dupou-Cézanne, L., Lopez, A. \& Tournier, J. F. (1989). Lipid lateral diffusion and membrane organization. FEBS Lett 257, 10-16.

Treptow, N. A. \& Shuman, H. A. (1985). Genetic evidence for substrate and periplasmic binding - protein recognition by the
MalF and MalG proteins, cytoplasmic membrane components of the Escherichia coli maltose transport system. J Bacteriol 163, 654-660.

Vogele, R. T., Sweet, G. D. \& Boos, W. (1993). Glycerol kinase of Escherichia coli is activated by interaction with the glycerol facilitator. J Bacteriol 175, 1087-1094.

Waldman, F. M., Hadley, W. K., Fulwyler, M. J. \& Schachter, J. (1987). Flow cytometric analysis of Chlamydia trachomatis interaction with L cells. Cytometry 8, 55-59.

Walker, E. M., Zampighi, G. A., Blanco, D. R., Miller, J. N. \& Lovett, M. A. (1989). Demonstration of rare protein in the outer membrane of Treponema pallidum subsp. pallidum by freezefracture analysis. J Bacteriol 171, 5005-5011.

Walker, E. M., Borenstein, L. A., Blanco, D. R., Miller, J. N. \& Lovett, M. A. (1991). Analysis of outer membrane ultrastructures of pathogenic Treponema and Borrelia species by freeze-fracture electron microscopy. J Bacteriol 173, 5585-5588.

Received 16 January 2001; accepted 2 February 2001 